\title{
Development of ligand-dependent regulatory system and its application to gene therapy of insulin-dependent diabetes mellitus
}

\author{
Jong-Min $\mathrm{Kim}^{1}$, Soo-Jin $\mathrm{Kim}^{2}$, \\ Hyun-Chul Lee ${ }^{2}$ and Kyung-Sup Kim ${ }^{1,3}$ \\ ${ }^{1}$ Department of Biochemistry and Molecular Biology \\ Institute of Genetic Science \\ 2Division of Endocrinology \\ Department of Internal Medicine \\ Yonsei University College of Medicine \\ Seoul 120-752, Korea \\ ${ }^{3}$ Corresponding author: Tel, 82-2-2228-1677; \\ Fax, 82-2-312-5041; E-mail, kyungsup59@yumc.yonsei.ac.kr
}

Accepted 9 June 2006

Abbreviations: ACL, ATP citrate-lyase; $A D$, activation domain; $D B D$, DNA binding domain; LBD, ligand binding domain; SIA, single-chain insulin analogue; SREBP, sterol regulatory element binding protein

\begin{abstract}
To develop an inducible expression system, the enhanced artificial nuclear receptors and target reporters were constructed. Artificial nuclear receptors were generated by fusing three domains, consisting of DNA-binding domain (DBD) of GAL4, ligand binding domain (LBD) of progesterone or estrogen receptor, and activation domain (AD) of VP16, sterol regulatory element binding protein (SREBP)-1a, or SREBP-2. The activation domain of SREBP-1a showed most potent transcriptional activity. The maximal level of target reporter gene expression was extremely elevated by the usage of ATP citrate-lyase (ACL) minimal promoter $-60 /+67$ in place of artificial TATA promoter, while the SV40 enhancer severely increased the basal transcription in the absence of ligand. The induction system, developed in the present study, was applied to cell therapy, resulting in successful induction of single-chain insulin analogue (SIA) gene expression to correct the hyperglycemia in diabetic animals. By means of subcutaneous cell therapy, the SIA gene expression rapidly occurred after the local topical application of ligand. These results suggest that our system represents a powerful tool for transcriptional regulation of target gene that can be used for diverse applications, ranging from basic research to gene therapy.
\end{abstract}

Keywords: ATP citrate (pro-S)-lyase; diabetes mellitus, type 1; gene therapy; insulin; receptors, estrogen; receptors, progesterone; sterol regulatory element binding protein 1

\section{Introduction}

Inducible expression systems could provide invaluable tools for basic research to elucidate the functions of specific gene product in physiological process, as well as many diverse applications, including the generation of transgenic or knock-out animal (Gingrich and Roder, 1998), and the controlled administration of gene products in gene therapy (Roscilli et al., 2002; Malphettes and Fussenegger, 2006). The ideal inducible expression system should have several characteristics. First, gene expression should be tightly controlled by the on/off system. Second, the gene expression should be enough low in basal not to develop undesired effects and could be induced to sufficiently high levels to obtain a physiological response. Third, regulatory inducers should be nontoxic and should not alter the expression of endogenous genes. Several inducible expression systems with the above characteristics have been developed. To develop an inducible expression system, artificial transcription factor or artificial nuclear receptor as transcription regulator, and target reporter are prerequisite. A number of transcription regulators have been generated by various means, using the DNA-binding domains (DBD) originated from yeast or prokaryote transcription factors such as GAL4 (Marmorstein et al., 1992), LexA (Szuts and Bienz, 2000) and TetR (Gossen and Bujard, 1992). Also, ligand binding domains (LBD) of several nuclear hormone receptors (Braselmann et al., 1993; Wang et al., 1994; Burcin et al., 1999), and activation domains (AD) derived from herpes simplex virus (Baim et al., 1991; Gossen and Bujard, 1992; Braselmann et al., 1993; Wang et al., 1994; Burcin et al., 1999) have been the most widely used.

Here, we describe an inducible expression system with several important improvements. Artificial nuclear receptors were rendered more potent and immunologically improved by usage of nonviral strong activation domains originated from human sterol regulatory element binding protein (SREBP) transcription factors, instead of viral VP16 AD. 
Several target reporter constructs were also developed, which show different basal and induced levels. Using our enhanced inducible system, we successfully demonstrated that it works not only in vitro, but also in experimental mice.

\section{Materials and Methods}

\section{Construction of artificial nuclear receptor and target reporter}

The artificial nuclear receptor pG4-PR-VP16, pG4PR-BP1a and pG4-PR-BP2 were generated from pFA2-Elk1 (Stratagene) by inserting the cDNA of progesterone receptor (PR) LBD (amino acids 645-891) and herpesvirus VP16 activation domain (amino acids 411-487) or SREBP-1a activation domain (amino acids 1-79) or SREBP-2 activation domain (amino acids 1-79). SREBP-1a AD was obtained from pET-SREBP-1a (Moon et al., 2000) by BamHI/Sacl digestion. SREBP-2 AD was generated by PCR with primer set of 5'-GGCGAATTCAGATCCATGGACGACAGCGGC-3', 5'-CTGCTAGATCTGCTGCCACTGCTGCC-3' from pCS2 (Moon et al., 2000), and then digested with EcoRI/Bg/ll. VP16 AD was prepared from pACT (Stratagene) by digestion with $E c o R I / B g / l l$. First, pFA-Elk1 was digested with EcoRI/Sacl for insertion of SREBP-1a AD or EcoRI/ $B g / l$ for SREBP-2 AD and VP16 AD, and ligated with respective $A D$ cDNAs. Next, the Elk region was removed by digestion with $B a m \mathrm{HI} / E c o R I$ and then replaced with LBDs of progesterone or estrogen receptor. PR LBD cDNA was obtained by PCRamplification with primer set of 5'-AGCCAGGGATCCACTTTTTCACCAGGTCAA-3', 5'-CTGGATGAATTCATTCAAGCAGTACAGATG-3' from human breast cancer cDNA. Estrogen receptor (ER) LBD cDNA was also generated by PCR with primer set of 5'-CCAAGCGGATCCATGATCAAACGCTCTAAG-3', 5'-GGATGCGAATTCACGGCTAGTGGGCGCATG-3'. The LBD cDNA were digested with BamHI/EcoRI and substituted for Elk region. To generate the target reporter, GAL4 responsive elements were amplified from pFR-luc (Stratagene) using the primer set of 5'-AGTCGCGGCCGCGGTCGGAGTACT, 5'-AGTCGTCGACGGTACCAACAGTAC-3'. The PCR product was digested with Notl and $X b a l$ and cloned into the Notl and Xbal sites of the pBluescript II SK (+) (Stratagene). Then, the ATP citrate-lyase (ACL) minimal promoter $-60 /+67$ was inserted at $X b a l$ and Smal sites of this vector by blunt ligation. Resulting plasmid was cut at downstream of $A C L$ minimal promoter $-60 /+67$ with $\mathrm{Xhol}$ and ligated with Xhol/ Sall fragment isolated from pGL3-basic or pGL3enhancer in proper orientation, resulting in pGA-luc and pGE-luc. For construction of pGA-SIA, the luci- ferase gene was removed by HindIII/Xbal digestion and then single-chain insulin analogue (SIA) gene was inserted at EcoRV site between ACL minimal promoter $-60 /+67$ and SV40 poly A signal. SIA gene was obtained by digestion with Sall/Hindlll of pLPK-SIA (Lee et al., 2000) and treatment with Klenow enzyme.

\section{Cell culture and transfection}

NIH3T3 cells obtained from ATCC were cultured in Dulbecco's modified Eagle's medium supplemented with $10 \%$ fetal bovine serum, $100 \mathrm{U} / \mathrm{ml}$ penicillin $\mathrm{G}$ sodium, $100 \mu \mathrm{g} / \mathrm{ml}$ streptomycin sulfate. All cell culture materials were purchased from Invitrogene. NIH3T3 cells were plated at a density of $2 \times 10^{5}$ cells/6-well dish. On the following day, transfection was performed with $1 \mu \mathrm{g}$ of DNA/well LipofectAMINE reagent (Invitrogene) according to the manufacturer's instruction. After $3 \mathrm{~h}$, DNA-Lipofectamine complex was removed and the media was replaced with fresh media. Twenty-four hours after transfection, gene expression was induced by medium change to $1 \mu \mathrm{M}$ of RU486 or $17 \beta$-estradiol containing media. Two days after transfection, cells were washed with phosphate-buffered saline (Invitrogene) and lysed in $200 \mu$ l of reporter lysis buffer (Promega). Luciferase activities were measured using the Luciferase Assay System (Promega) and normalized with $\beta$-galactosidase activities to correct the transfection efficiency. All experiments were done in triplicate and were repeated at least twice.

\section{Animal experiments}

7-week-old BALB/C male mice (Daehan Biolink, Korea) were used. Animals were administered 50 $\mathrm{mg} / \mathrm{kg}$ of streptozotocin (Sigma) intra-peritoneally (i.p). Animals were confirmed to be diabetic above $400 \mathrm{mg} / 100 \mathrm{ml}$ blood glucose level and experiments were performed. About $3 \times 10^{6} \mathrm{NIH} 3 \mathrm{~T} 3$ cells in two $100-\mathrm{mm}$ dishes were transfected with $13.5 \mu \mathrm{g}$ of target gene and $1.5 \mu \mathrm{g}$ of artificial nuclear receptor. Twenty-four hours after transfection, about $1.2 \times 10^{7}$ cells were harvested with trypsin and suspended in $500 \mu$ of DMEM. The cell suspension was injected into subcutaneous tissue on the interscapular region, using 19-gauge needle. The backs of animals were completely shaved before the transplantations and we marked the region of the skin bulge by cell suspension after the transplantations. Two days after transplantation, $50 \mu \mathrm{l}$ of RU486 $(4 \mathrm{mg} / \mathrm{ml}$ in ethanol) or $50 \mu$ of $17 \beta$-estradiol $(2 \mathrm{mg} / \mathrm{ml}$ in ethanol) solution were topically applied by slowly dropping them on the marked skin covering the transplantation and blood glucose levels were determined in blood obtained through tail bleeds. 


\section{Results}

\section{Construction of the ligand-dependent inducible gene expression systems}

Artificial transcription factors have similar structure to the nuclear hormone receptors. They are composed of three functionally distinctive domains, DBD, LBD, and AD. We prepared two kinds of inducible expression systems based on LBD's derived from progesterone receptor (amino acids 645-891) or estrogen receptor (amino acids 279-554). The LBD of PR used in present study is the mutated form by deleting C-terminal 42 amino acids. The deleted form of PR LBD to which progesterone cannot bind, can avidly interact with progesterone antagonist, RU486, and thus enable to generate the inducible system to respond only to exogenous ligand but not to endogenous progesterone. In order to increase the activation potential of artificial transcription factor, we examined the three activation domains originated from VP16 (amino acids 411-487), SREBP-1a (amino acids 1-79) or SREBP-2 (amino acids 1-79). The N-terminal acidic domain of SREBP1a was well known to be potent activation domain interacting coactivators, such as CBP/p300 and ARC/DRIP (Oliner et al., 1996; Naar et al., 1998; Naar et al., 1999). For DNA-binding specificity, we used DBD of GAL4 (amino acids 1-148), which is well known yeast transcription factor and does not affect the mammalian gene expression (Carey et al., 1989; Marmorstein et al., 1992). Artificial nuclear receptors were generated by joining these domains in order of DBD, LBD and $A D$ from $\mathrm{N}$-terminus (Figure $1 \mathrm{~A})$. In order to test the transcriptional

A

\begin{tabular}{|c|c|c|c|}
\hline & & $\begin{array}{l}\text { PR } \\
\text { ER } \\
\end{array}$ & $\begin{array}{l}\text { VP16 } \\
\text { BP-1a } \\
\text { BP-2 }\end{array}$ \\
\hline Activator & $\begin{array}{l}\text { GAL4 } \\
\text { DBD }\end{array}$ & LBD & $A D$ \\
\hline
\end{tabular}
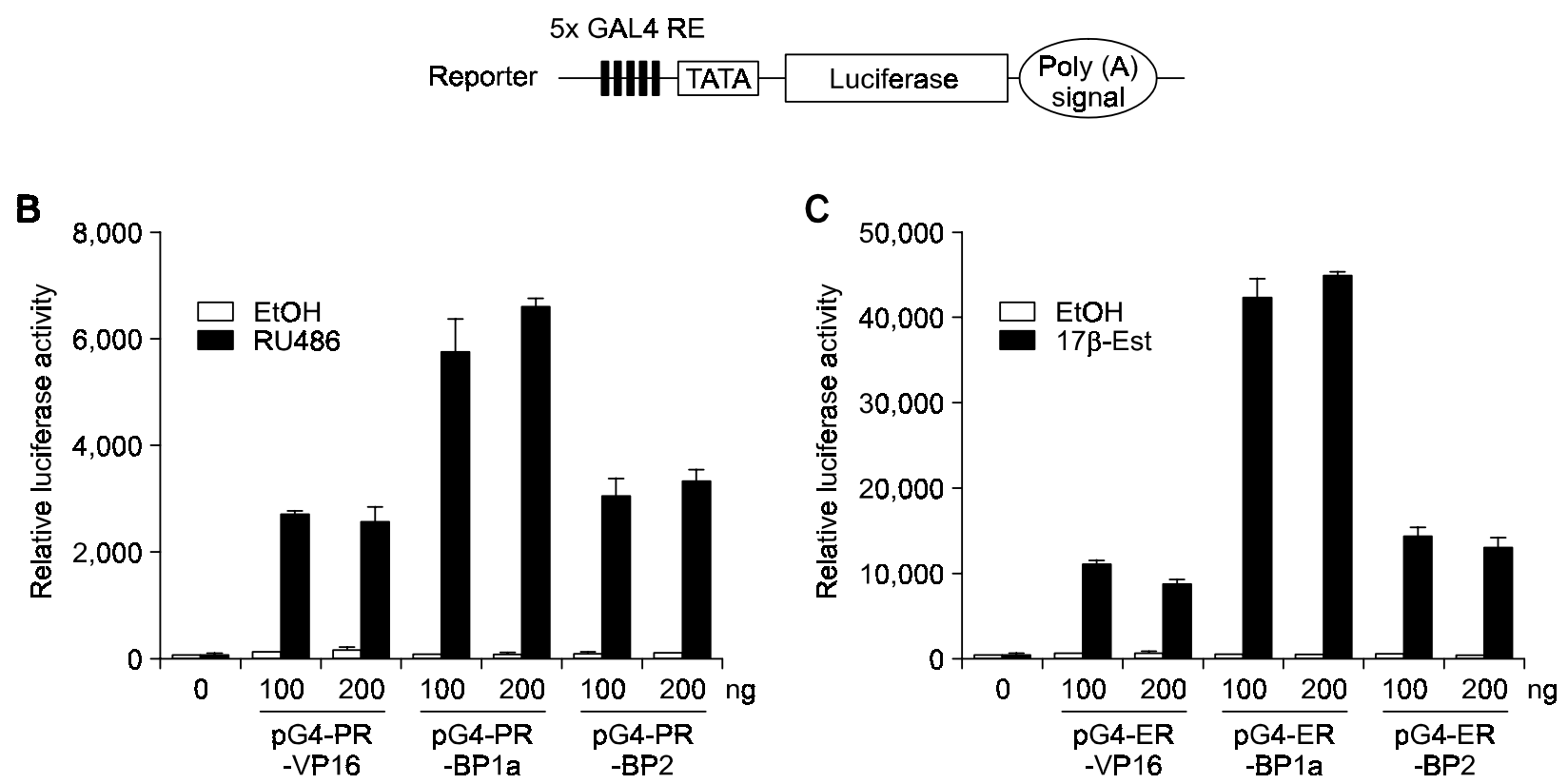

Figure 1. PR LBD- and ER LBD-based inducible expression system for the control of gene expression. (A) Diagram of artificial nuclear receptor and target reporter constructs used in the inducible expression system. The artificial nuclear receptor consists of DBD of yeast transcriptional activator GAL4, LBD of progesterone or estrogen receptor, and AD of VP16 or SREBP-1a or SREBP-2, respectively. Resulting plasmids expressing these nuclear receptors under the control of CMV promoter were constructed, and named as pG4-PR-VP16, pG4-PR-BP1a, and pG4-PR-BP2 in PR LBD-based constructs, and pG4-ER-VP16, pG4-ER-BP1a, and pG4-ER-BP2 in ER LBD-based constructs. The reporter construct, pFR-Luc, has 5 copies of GAL4 response element (17mer) at the upstream of artificial TATA box promoter followed by the luciferase gene. (B, C) NIH-3T3 cells were transfected with $0.6 \mu \mathrm{g}$ of pFR-luc, $0.2 \mu \mathrm{g}$ of pCMV- $\beta$-gal and various amounts ( 0 to $200 \mathrm{ng}$ ) of the indicated artificial nuclear receptor. The total amount of transfected plasmids was adjusted to $1 \mu \mathrm{g}$ by addition of pcDNA3. Twenty-four hours after transfection, cells were either left untreated or 1 $\mu \mathrm{M}$ of RU486 (B) or 17 $\beta$-estradiol (C) was added. Two days after transfection, cells were harvested and the luciferase activities were assayed. The reporter activities are shown as the relative luciferase activity normalized by the $\beta$-galactosidase activity. Values represent the mean \pm S.D of three independent experiments. 
activity of artificial nuclear receptors, we employed a reporter construct, pFR-Luc, which have minimal promoter consisting of 5 copies of Gal4 response element (17mer) and artificial TATA box, controlling the expression of luciferase gene (Figure 1A).

\section{Ligand-dependent transactivation by artificial nuclear receptors in transient transfection assay}

We transfected CMV promoter-driven artificial nuclear receptor expression constructs along with the reporter construct pFR-Luc into NIH3T3 cells in order to check the availability of our inducible expression systems. Figure $1 \mathrm{~B}$ and $\mathrm{C}$ showed the ligand-dependent transcriptional activity of artificial nuclear receptors. As shown in Figure 1B, progesterone antagonist, RU486, could induce transcriptional activity of pG4-PR-VP16, pG4-PR-BP1a and pG4-PR-BP2. When using the VP16 AD, basal transcriptional activity in the absence of ligand was about 2 times higher than other artificial receptors. The artificial nuclear receptors that contained ADs of SREBPs showed relatively small background activity and high inducibility. Among three artificial nuclear receptors, pG4-PR-BP1a was the most profitable for the inducible gene expression systems because it showed lower background activity and highest inducible transcriptional activity by ligand. These results could be also applied to ER LBD-based system. However ligand-dependent transcriptional activation of the ER LBD-based systems is much stronger than PR LBD-based systems. The results demonstrate that $A D$ of SREBP-1a is more excellent than those of VP16 and SREBP-2 in points of low basal activity and high induction folds, leading us to

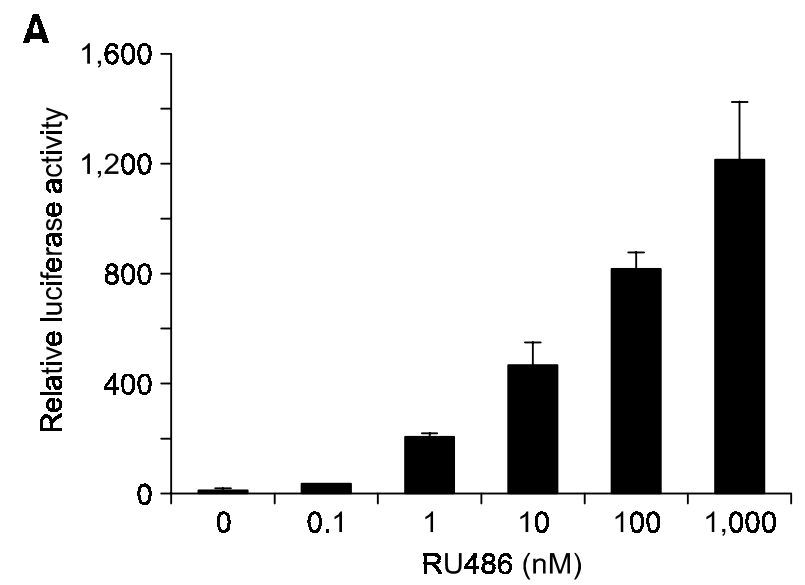

use the artificial transcription factors containing $A D$ of SREBP-1a in remaining all experiments.

We next examined the ability of the artificial nuclear receptor to induce the target gene expression over a range of ligand concentrations (Figure 2). In PR LBD-based system, ligand-dependent activation showed to be proportional to the ligand concentrations up to $1,000 \mathrm{nM}$, whereas in ER LBDbased system, reporter gene activation was markedly induced from 0.1 to $1 \mathrm{nM}$ and was already saturated at $10 \mathrm{nM}$. These results suggested that in PR LBD-based system, the levels of the expression of target gene could be controlled by the concentration of RU486, while ER LBD-based inducible factor has the characteristics of the on/off system.

\section{Construction of target reporter constructs showing different expression levels}

Even though the inducibility appeared to be high due to minimal basal expression, the induction of target gene expression might not reach to therapeutic doses. In these cases, the therapeutic doses of inducible system, such as DNA or modified cells, must be increased. Another strategy to circumvent these problems is to elevate the absolute amounts of the induced gene expression by increasing the basal expression to maximum level not to produce undesired effects. In present study, we introduced the ACL minimal promoter instead of artificial TATA promoter to increase the expressed levels by artificial transcription factor, resulting in construction of pGA-Luc (Figure 3A). And to further increase the basal promoter activity, the SV40 enhancer sequence was inserted into the downstream of the poly

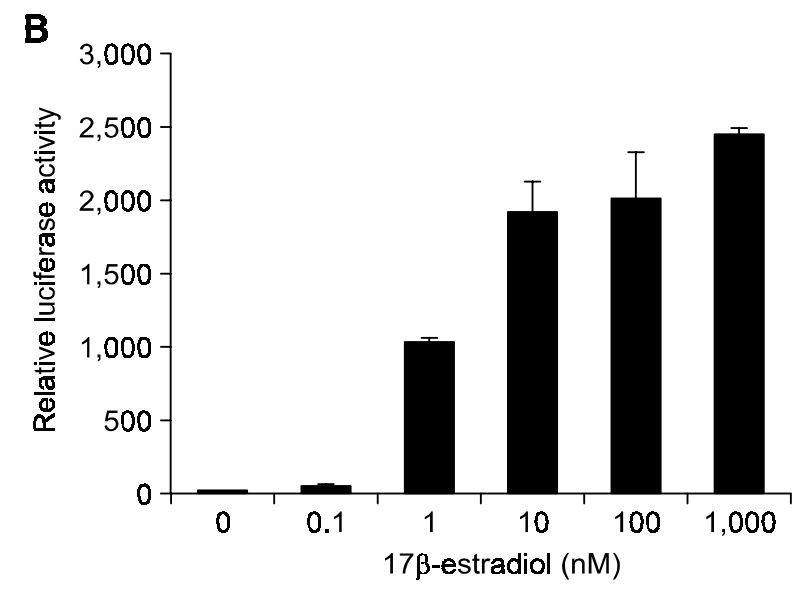

Figure 2. Transcriptional activation of the inducible expression system is dependent on RU486 or 17ß-estradiol concentration. NIH-3T3 cells were transfected with $0.6 \mu \mathrm{g}$ of pFR-luc, $0.2 \mu \mathrm{g}$ of pCMV- $\beta \mathrm{gal}$ and $100 \mathrm{ng}$ of pG4-PR-BP1a (A) or pG4-ER-BP1a (B). Twenty-four hours after transfection, cells were treated with various concentration (0-1 $\mu \mathrm{M}$ of RU486 (A) or 17ß-estradiol (B)). Two days after transfection, cells were harvested and the luciferase activities were assayed. The reporter activities are shown as the relative luciferase activity normalized by the $\beta$-galactosidase activity. Values represent the mean \pm S.D of three independent experiments. 
A
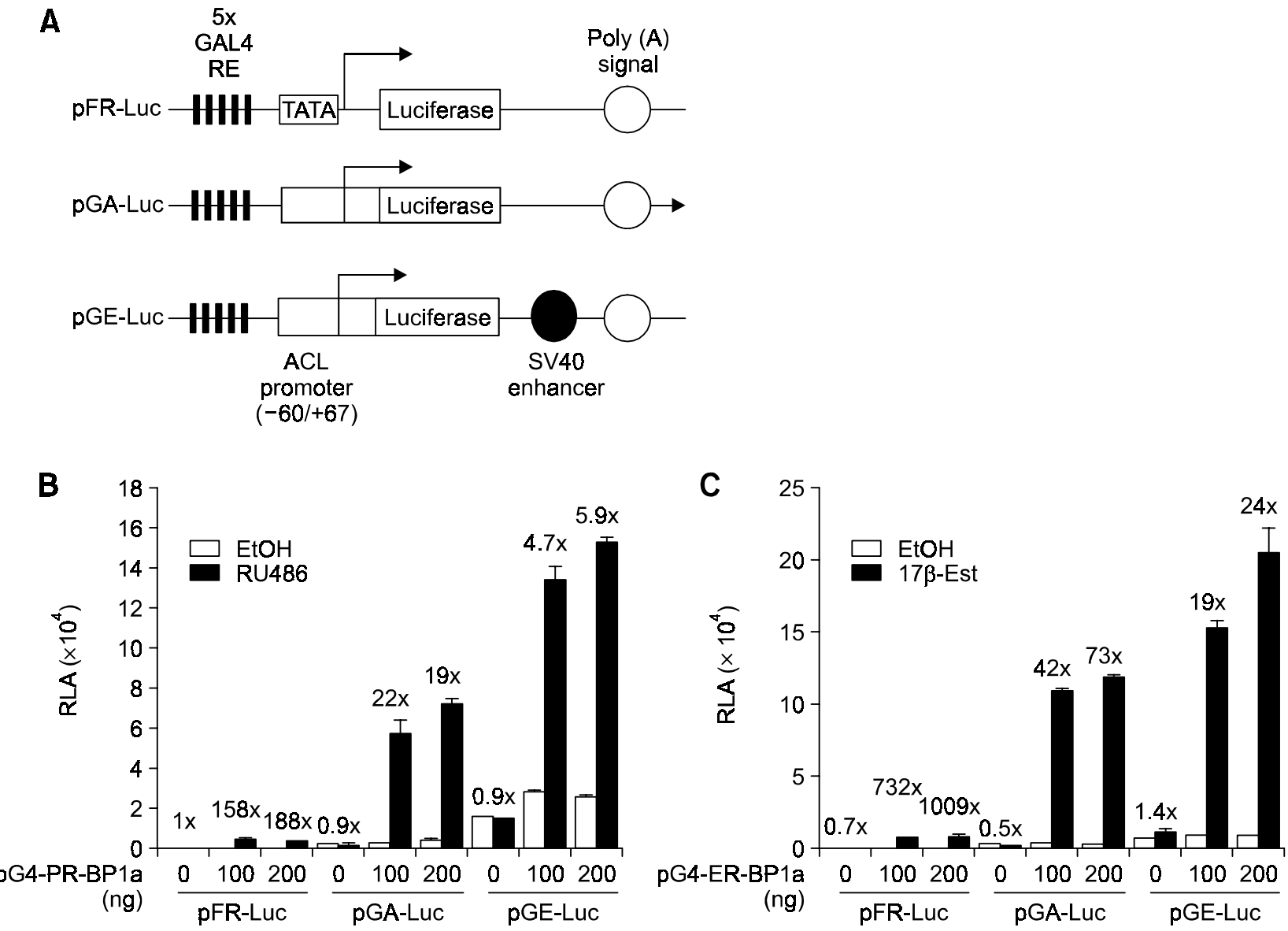

Figure 3. Comparison of gene expression by modified target reporter. (A) Diagram of target reporter constructs. Target reporter pGA-luc contains the ACL minimal promoter $-60 /+67$, pGE-luc contains the ACL minimal promoter $-60 /+67$ and SV40 enhancer. (B, C) NIH-3T3 cells were transfected with $0.6 \mu \mathrm{g}$ of the indicated reporters, $0.2 \mu \mathrm{g}$ of pCMV- $\beta$ gal and various amounts ( 0 to $200 \mathrm{ng}$ ) of pG4-PR-BP1a (B) or pG4-ER-BP1a (C). Twenty-four hours after transfection, cells were either left untreated or $1 \mu \mathrm{M}$ RU486 (B) or 17ß-estradiol (C) was added. Two days after transfection, cells were harvested and the luciferase activities were assayed. The reporter activities are shown as the relative luciferase activity normalized by the $\beta$-galactosidase activity. Values represent the mean \pm S.D of three independent experiments. Numbers above the black bars indicate the ratios of ligand-induced activities in comparison to basal activities in absence of ligand.

(A) signal, resulting in pGE-Luc (Figure $3 \mathrm{~A}$ ). As shown in Figure 3B, pFR-luc showed highest ligand-dependent induction folds by pG4-PR-BP1a and pG4-ER-BP1a, but the levels of ligand-induced reporter gene expression is very low in comparison to those of pGA-luc. The replacement of artificial TATA box promoter with ACL minimal promoter markedly elevated the basal promoter activity to 140 fold. The addition of SV40 enhancer, resulting in pGE-Luc, further increased the basal activity up to 1200 folds, which is 8 fold higher than the value of ligand-induced promoter activities of pFR-luc in PR LDB based-system. In the ligand-dependent inductions of pGA-luc by pG4-PR-BP1a and pG4-ER-BP1a were 16 and 25 folds higher than those of pFR-Luc.

In summary, pFR-Luc showed almost absence of basal promoter activity and highest inducibility, and
pGE showed very high basal expression, whereas pGA-Luc might have moderate basal activity and much effective inducibility. As results, we tested the pGA reporter system for the application to gene therapy in the diabetic animals.

\section{In vivo application of inducible gene expression system}

To test the feasibility of our inducible expression system in experimental mice, we generate the target gene construct $\mathrm{pGA}-\mathrm{SIA}$, which was generated by substitution of single-chain insulin analogue (SIA) gene for luciferase gene in pGA-luc (Lee et al., 2000). We chose SIA as a target gene, because SIA possesses biologically active insulin activity by itself without proteolytic process. The NIH3T3 cells were 
A

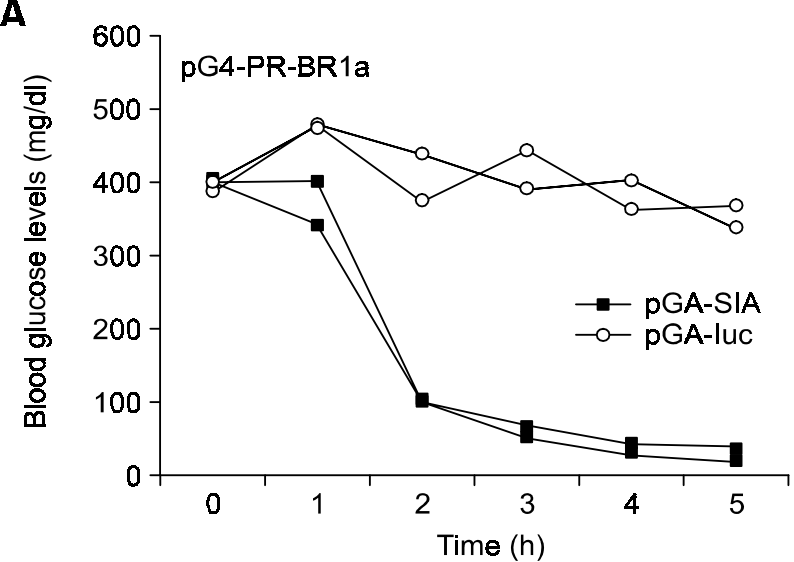

B

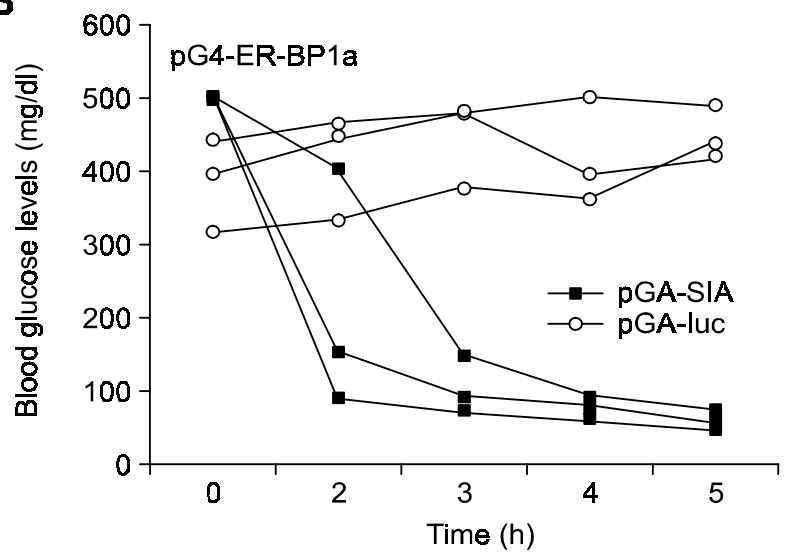

Figure 4. Conditional expression of SIA gene in subcutaneously transplanted fibroblasts, which were transfected with SIA-inducible system. NIH3T3 fibroblasts were transfected with $13.5 \mu \mathrm{g}$ of pGA-luc (open symbols) or pGA-SIA (closed symbols) and $1.5 \mu \mathrm{g}$ of pG4-PR-BP1a (A) or pG4-ER-BP1a (B) per a $10 \mathrm{~cm}$ plate. Twenty-four hours after transfection, about $1.2 \times 10^{7}$ cells were harvested with trypsin and suspended in $500 \mu \mathrm{l}$ of DMEM. The cell suspension was subcutaneously injected at interscapular region of each streptozotocin (STZ)-induced diabetic mice. Two days after transplantation, $50 \mu \mathrm{l}$ of RU486 (4 mg/ml in ethanol) or $17 \beta$-estradiol $(2 \mathrm{mg} / \mathrm{ml}$ in ethanol) solution were topically applied to the region of transplantation and blood glucose levels were determined in blood obtained through tail bleeds. Each data represents an individual mouse.

cotransfected with the expression construct of the artificial nuclear receptor and the target gene pGA-SIA, and then followed by transplantation of the cells into the interscapular region of STZ-induced diabetic BALB/C mice, subcutaneously. After transplantation, high blood glucose levels were not changed at all. Two days after transplantation, $50 \mu \mathrm{l}$ of RU486 (4 mg/ml in ethanol) or $50 \mu \mathrm{l}$ of $17 \beta-$ estradiol $(2 \mathrm{mg} / \mathrm{ml}$ in ethanol) solution were topically applied to the region of transplantation. The blood glucose levels started to decrease at $2 \mathrm{~h}$ and reached to hypoglycemic state at $5 \mathrm{~h}$ after ligand administration in both experiments of pG4-PR-BP1a and pG4-ER-BP1a, whereas pGA-Luc did not significantly affected the blood glucose levels (Figure 4A and $4 \mathrm{~B}$ ). The hypoglycemia at $5 \mathrm{~h}$ could be corrected within $2 \mathrm{~h}$ after washing out the skin with ethanol and administration of glucose (data not shown). In this experiment, we show that our inducible expression system has a fast and sufficient induction of SIA gene to treat hyperglycemia in vivo.

\section{Discussion}

Inducible expression systems have been very useful tools in the gene function study, the generation of animal models of disease and the gene therapy. Several inducible expression systems have been used successfully to regulate transgene expression in cultured cells, in transgenic mice, and in mice injected with viral vectors (Braselmann et al., 1993; Wang et al., 1994; Wang et al., 1997; Burcin et al., 1999; Wang et al., 1999; Cronin et al., 2001; Cao et al., 2002). Wang et al (1994) have developed PR LBD-based inducible expression system, which uses a chimeric transcription regulator, GLVP, constructed by fusing the ligand binding domain of the mutant human progesterone receptor to the yeast transcriptional activator GAL4 DBD and the herpes simplex virus protein VP16 AD. Also, Braselmann et al (1993) have developed ER LBD-based inducible expression system using a chimeric molecule, GAL-ER-VP16, consisting of the estrogen receptor, GAL4 DBD, and the VP16 AD, which induced the reporter gene at least 100 folds. Although the VP16 $A D$ was commonly used as a activation domain in the construction of artificial transcription factors, VP16 protein has a higher probability that could cause an immune response in human. Moreover, the high expression levels of the VP16 AD are known to have squelching effect, which can be toxic to cells. Therefore, to minimize possible toxicity and immunogenic reactions of these inducible expression systems for human gene therapy, the mammalian transcription factor ADs has been used instead of VP16 AD. Brucin et al (1999) constructed the regulator GLp65, which consists of the GAL4 DBD, PR $L B D$, and $A D$ of human $p 65$, a partner of NF- $K B$ in the human RelA heterodimeric transcription factor. As a result, the possible toxicity of this system was decreased. The regulator GLp65 has a similar potency in the induction of target gene expression in transient transfection when compared with GLVPc, which consists of the GAL4 DBD, PR LBD, and VP16 AD.

The AD of human SREBP-1a, used in this experiment, showed much more potency in ligand- 
dependent induction system, than those of VP16 or SREBP-2. Induction ratio of the PR LBD-based system was 158- to 183-fold, up to 3 times higher than that of previous reported system and ER LBD-base system was 732- to 1009-fold, 7 - to 10 times higher than that of previous reported system (Braselmann et al., 1993; Burcin et al., 1999). Because basal expression of artificial TATA box in pFR-luc is very low, the induced expression of target gene was also relatively low in spite of extremely high induction folds. If this reporter system were applied to gene therapy, the effective treatment would require the high copy number of target genes or large number of the cells containing the target gene. To minimizes the transduction dose of target gene or the numbers of the cells modified by gene transduction, the basal expression level of reporter construct should be increased to relatively high level to be tolerated in non-induced state. In present study, ACL minimal promoter $-60 /+67$, in place of artificial TATA promoter, was used to increase the basal expression. ACL is a cytosolic enzyme that catalyzes the cleavage of citrate into oxaloacetate and acetyl-CoA (Kornacker and Ball, 1965). The activity of ACL is mainly regulated at transcriptional level in response to dietary status and insulin, like other lipogenic enzymes (Kim et al., 1992). ACL promoter activity was increased by the overexpression of SREBP-1a and SREBP-2. However, the ACL minimal promoter $-60 /-67$ shows very low basal activity and did not respond to SREBPs (Moon et al., 2000). ACL minimal promoter $-60 /+67$ drastically elevated the ligand-induced expression levels, which were 16 and 25 folds higher than those of artificial TATA promoter. This increase might not only be derived from increased transcription, but also probably from increased mRNA stability and its translation due to 5' UTR of ACL. However, the addition of SV40 enhancer severely elevates the basal expression, which was much higher than the ligand-induced expression of artificial TATA promoter.

To supply the insulin to the diabetic animals, we generated the fibroblasts containing inducible insulin analogue (SIA) expression system and transplanted into diabetic animals subcutaneously. Initially, we used the minimal TATA promoter for SIA expression, but the blood glucose levels were not affected at all after ligand treatment (data not shown), suggesting that the levels of ligand-dependent SIA expression were much less than the doses to drop blood glucose levels in diabetic animals. Next, we did same experiments using pGA-SIA containing ACL minimal promoter and demonstrated that our inducible expression system has a fast kinetics induction, which shows tight on/off control by ligand in vivo. Because the steroid sex hormones had the enormous actions in mammals, local topical application of hormones could minimize their systemic action. Previously, therapeutic proteins, which were expressed in skin of transgenic animal, reported to be delivered successfully into circulation (Wang, et al., 1999; Cao et al., 2002). SIA protein also showed the rapid delivery from subcutaneous tissue into circulation. Topical application of steroid hormones onto skin could achieve rapid induction of SIA and enable the induced transcription of SIA gene to easily be terminated by washing out topical applicants. In case of diabetes, the secretion of insulin very rapidly occurs to large extent during the short postprandial period. However, it is impossible to induce the expression for short period by systemic administration of steroid hormones due to their long half-life. If the capacity of target gene expression level were sufficient, topical short-time application of inducer might enable rapid quantitative secretion of insulin for short period, similar to its physiological secretion pattern. For these goals, we tried to increase absolute expression level of target gene induced by ligand by replacement of activation domain of artificial nuclear receptor and changing the minimal promoter of its reporter construct, and we show that our inducible expression system has a fast and sufficient induction of SIA gene to correct hyperglycemia in vivo.

In conclusion, we generated the inducible expression system with several important improvements. This enhanced inducible expression system would not only be useful for analyzing the function of exogenous gene, but may also be implemented in gene therapy protocols in which a therapeutic gene is delivered.

\section{Acknowledgment}

This study was supported by a grant from the Myung Sun Kim Memorial Foundation (2000).

\section{References}

Baim SB, Labow MA, Levine AJ, Shenk TA. Chimeric mammalian transactivator based on the lac repressor that is regulated by temperature and isopropyl beta-D-thiogalactopyranoside. Proc Natl Acad Sci USA 1991;88:5072-76

Braselmann S, Graninger P, Busslinger M. A selective transcriptional induction system for mammalian cells based on Gal4-estrogen receptor fusion proteins. Proc Natl Acad Sci USA 1993;90:1657-61

Burcin MM, Schiedner G, Kochanek S, Tsai SY, O'Malley BW. Adenovirus-mediated regulable target gene expression in vivo. Proc Natl Acad Sci USA 1999;96:355-60 
Cao T, Tsai SY, O'Malley BW, Wang XJ, Roop DR. The epidermis as a bioreactor: topically regulated cutaneous delivery into the circulation. Hum Gene Ther 2002;13:1075-80

Carey M, Kakidani H, Leatherwood J, Mostashari F, Ptashne M. An amino-terminal fragment of GAL4 binds DNA as a dimer. J Molecular Biology 1989;209:423-32

Cronin CA, Gluba W, Scrable H. The lac operator-repressor system is functional in the mouse. Genes Dev 2001;15: 1506-17

Gingrich JR, Roder J. Inducible gene expression in the nervous system of transgenic mice. Annu Rev Neurosci 1998;21: 377-405

Gossen M, Bujard H. Tight control of gene expression in mammalian cells by tetracycline-responsive promoters. Proc Natl Acad Sci USA 1992;89:5547-51

Kim KS, Park SW, Kim YS. Regulation of ATP-citrate lyase at transcriptional and post-transcriptional levels in rat liver. Biochem Biophys Res Commun 1992;189:264-71

Kornacker MS, Ball EG. Citrate cleavage in adipose tissue. Proc Natl Acad Sci USA 1965;54:899-904

Lee HC, Kim SJ, Kim KS, Shin HC, Yoon JW. Remission in models of type 1 diabetes by gene therapy using a single-chain insulin analogue. Nature 2000;408:483-88

Malphettes L, Fussenegger M. Improved transgene expression fine-tuning in mammalian cells using a novel transcription-translation network. J Biotechnol 2006; in press

Marmorstein R, Carey M, Ptashne M, Harrison SC. DNA recognition by GAL4: structure of a protein-DNA complex. Nature 1992;356:408-14

Moon YA, Lee JJ, Park SW, Ahn YH, Kim KS. The roles of sterol regulatory element-binding proteins in the transactivation of the rat ATP citrate-lyase promoter. J Biol Chem 2000;275: 30280-86

Naar AM, Beaurang PA, Robinson KM, Oliner JD, Avizonis D, Scheek S, Zwicker J, Kadonaga JT, Tjian R. Chromatin, TAFs, and a novel multiprotein coactivator are required for synergistic activation by Sp1 and SREBP-1a in vitro. Genes Dev 1998;12:3020-31

Naar AM, Beaurang PA, Zhou S, Abraham S, Solomon W, Tjian R. Composite co-activator ARC mediates chromatin-directed transcriptional activation. Nature 1999;398:828-32

Oliner JD, Andresen JM, Hansen SK, Zhou S, Tjian R. SREBP transcriptional activity is mediated through an interaction with the CREB-binding protein. Genes Dev 1996;10:2903-11

Roscilli G, Rinaudo CD, Cimino M, Sporeno E, Lamartina S, Ciliberto G, Toniatti C. Long-term and tight control of gene expression in mouse skeletal muscle by a new hybrid human transcription factor. Mol Ther 2002;6:653-63

Szuts D, Bienz M. LexA chimeras reveal the function of Drosophila Fos as a context-dependent transcriptional activator. Proc Natl Acad Sci USA 2000;97:5351-56

Wang XJ, Liefer KM, Tsai S, O'Malley BW, Roop DR. Development of gene-switch transgenic mice that inducibly express transforming growth factor beta1 in the epidermis. Proc Natl Acad Sci USA 1999;96:8483-88

Wang Y, DeMayo FJ, Tsai SY, O'Malley BW. Ligand-inducible and liver-specific target gene expression in transgenic mice. Nat Biotechnol 1997;15:239-43

Wang Y, O'Malley BW Jr, Tsai SY, O'Malley BW. A regulatory system for use in gene transfer. Proc Natl Acad Sci USA 1994; 91:8180-84 